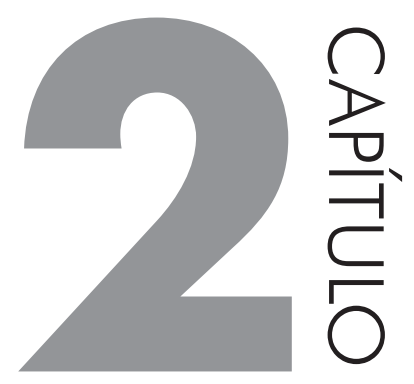

\title{
IMPACTOS DA ÁGUA DE LASTRO NO AMBIENTE
}

\section{NEWTON NARCISO PEREIRA, HERNANI LUIZ BRINATI}

\subsection{ESPÉCIES INVASORAS}

Espécies introduzidas em locais diferentes de sua origem são conhecidas como espécies invasoras, alienígenas, exóticas, estrangeiras, não nativas e não indígenas (MEDEIROS, 2004). Deste modo, uma espécie invasora pode ser definida como aquela que foi transferida de um local para outro e conseguiu se estabelecer no novo habitat. Existem diversos mecanismos para a transferência de espécies, tais como veículos, animais, ação da natureza, entre outros. Assim, muitas espécies são diariamente importadas e exportadas de um local para outro, sendo que em alguns casos ocorre o estabelecimento destas espécies (CARLTON et al., 1995).

Para uma espécie se estabelecer em um novo local ela deve encontrar condições similares ao seu local de origem. Muitas vezes a transferência de uma espécie não nativa pode gerar uma série de problemas para o ecossistema local. Assim, pode-se transferir um predador voraz que poderá dizimar uma espécie nativa e se estabelecer, sem que haja para o invasor um predador natural.

A liberação das espécies não nativas em um ambiente novo constitui uma inoculação, mas sua introdução pode não ser necessariamente bem sucedida (CARLTON et al., 1995). Não se sabe por quanto tempo a maioria dos indivíduos 
inoculados sobrevive. Indivíduos mais velhos, isolados das espécies não nativas, são encontrados ocasionalmente, o que indica que certo número cresce até a fase adulta (COHEN e CARLTON, 1995).

Embora o processo de introdução seja de difícil equacionamento, devido ao número de variáveis envolvidas, tanto físico-químicas quanto ambientais, são inúmeros os registros de invasões de espécies exóticas no mundo.

Onde e quando uma nova espécie vai se estabelecer é o principal problema gerado pelas milhares de espécies exóticas transportadas diariamente nos tanques de lastro dos navios. Organismos que sobrevivem às condições adversas de uma viagem, no interior de um tanque de lastro ou fixada no seu casco, bem como em outros elementos do navio como tubulações, correntes, ancoras e hélices, são considerados espécies resistentes (MEDEIROS, 2004).

Obviamente não se pode atribuir que toda bioinvasão proveniente dos navios seja oriunda somente da água de lastro, mas ela carrega a maior parte das espécies. Estimou-se que nos anos 90, mais de 3.000 espécies de animais e plantas foram transportadas diariamente ao redor do mundo dentro dos tanques de lastro dos navios (GLOBALLAST, 2003). Há consenso de que o número de espécies introduzidas mediante a água de lastro está crescendo continuamente (GOLLASCH, 2007).

A European Maritime Safety Agency explica que o número de espécies transportadas diariamente pode chegar a cerca de 10 mil indivíduos das mais variadas espécies. Somente, nos EUA mais de 40 espécies apareceram nos Grandes Lagos desde 1960 e mais de 50 na Baía de São Francisco desde 1970 (RUIZ et al.,2000). Nos Estados Unidos, identificou-se o mexilhão Zebra, oriundo de água de lastro, pela primeira vez na década de 80 , quando se proliferou pelas águas dos rios rapidamente, causando sérios danos ao ecossistema (CALIFORNIA ENVIRONMENTAL PROTECTION AGENCY, 2002).

As três introduções mais notáveis de que se tem registro são o mexilhão-zebra nos EUA, os dinoflagelados (algas unicelulares) na Austrália, e a água-viva carnívora nos EUA, que resultaram em prejuízos da ordem de US\$ 10 bilhões e tiveram profundas e amplas repercussões ecológicas nos últimos anos $(\mathrm{BOLCH}$ e HALLEGRAEFF, 1993). Mais recentemente, Pimentel et al. (2004) e Oliveira (2008) apresentaram os resultados de um levantamento dos custos gerados pela bioinvasão no mundo, estimando-se que o valor gasto anualmente seja da ordem de 100 bilhões de dólares, incluindo todas as formas de bioinvasão.

Por outro lado, no Brasil, embora não existam informações relativas ao custo da bioinvasão, dispõe-se os registros de algumas novas espécies estabelecidas no litoral brasileiro provenientes da água de lastro. O caso mais notável é o mexilhão dourado "Limnoperna fortunei". Esta é uma espécie nativa de rios e arroios chineses e do sudeste asiático e, apenas recentemente, por razões desconhecidas, vem 
expandindo sua distribuição em todo o mundo (MANSUR et al. 2003; CARMO, 2006). Provavelmente, essa proliferação de espécies nativas da China, deve-se ao desenvolvimento econômico, que elevou a frequência de visita de navios em seus portos coletando cada vez mais água de lastro. Um exemplo disso é o aumento das exportações de minério de ferro para a China nos últimos anos.

Pestana et al. (2002) apud Darrigran (2002) explicam que do estuário da Bacia do rio Prata foi o local que o mexilhão dourado invadiu pela primeira vez na América do Sul, onde ele se expandiu rapidamente para os trechos superiores da Bacia do rio Paraná, invadindo principalmente os grandes rios, numa velocidade de cerca de $240 \mathrm{~km} / \mathrm{ano}$. Pestana et al. (2002) apud Oliveira et al. (2004) esclarecem que, em 2001, sua presença foi reportada na Usina de Itaipu e, em 2002, foi encontrado nas usinas hidrelétricas (Porto Primavera e Sérgio Motta) à jusante do Rio Paraná, em São Paulo. A entrada da espécie neste sistema de rios deve ter ocorrido através da intensa navegação e transposição de barcos utilizados na pesca esportiva.

O impacto do mexilhão dourado no Brasil tem sido grande e tem causado problemas de saúde pública, de entupimento de tubulações, de filtros de usinas hidroelétricas e de bombas de aspirações de água, a degradação das espécies nativas e problemas relacionados com a pesca (RESENDE, 2007).

Resende (2007) analisou o efeito da fixação do mexilhão dourado nas paredes e nas grades de tomadas d'água em usinas hidrelétricas. Verificou-se que estes elementos aderidos provocam uma perda de carga do sistema diminuindo o rendimento da usina e aumentando o impacto do fluxo de água sobre a grade, podendo no limite ocasionar um rompimento do sistema. As consequências deste problema e os custos que ele tem gerado para o sistema brasileiro são:

- Redução na eficiência das bombas e consequentemente aumento no consumo de energia para conseguir um funcionamento normal dos sistemas.

- Aumento da corrosão de encanamentos pela proliferação de outros agentes biológicos indesejáveis (bactérias, fungos etc.).

- Paralisação do sistema para limpeza ou substituição de tubulações, válvulas, filtros etc.

Em função destes efeitos prejudiciais, muitas hidroelétricas brasileiras estão tendo que fazer investimentos em sistemas de proteção e ajustes nos projetos. Para compensar a perda de carga, causada pela presença do mexilhão dourado nas tubulações, é necessário aumentar a carga nas bombas para atingir a mesma vazão de projeto e, consequentemente, em muitos casos ocorre aumento no consumo de energia. Contudo, o autor explica que ainda são necessários estudos para quantificar os custos reais deste processo. 
Mansur et al. (2003) examinaram junto ao Clube Náutico de Porto Alegre, os efeitos do mexilhão Zebra nas embarcações de turismo. Em apenas três meses após o lançamento de uma embarcação na água pode ocorrer avaria ou baixo rendimento do motor, devido ao entupimento de encanamentos de refrigeração, além do aumento de resistência do casco pelo efeito de incrustação. Observe-se ainda que o mexilhão dourado ataca outros seres vivos como conchas e também juncos.

Uma das principais características do mexilhão dourado é sua resistência às condições ambientais e sua alta fecundidade, sendo capaz de colonizar uma grande variedade de habitats. Suas colônias atingem densidades de mais de 150.000 indivíduos por metro quadrado (BELZ, 2006). Outra característica deste molusco é sua capacidade de sobrevivência em água doce. Geralmente, associam-se esses indivíduos a ambientes marinhos, mas ele expandiu-se por vários rios do sul do Brasil (ITAIPU, 2012).

Um dos principais receios dos pesquisadores na área é que o mexilhão dourado chegue às bacias amazônicas. A pesquisadora da Embrapa Márcia Divina de Oliveira comenta que a boa oferta de alimento e condições ambientais adequadas, como salinidade, temperatura, $\mathrm{pH}$ e disponibilidade de cálcio da água favorecem a proliferação do molusco. "Nos rios de águas ácidas, com $\mathrm{pH}$ abaixo de 5, o mexilhão tem baixo potencial de se estabelecer, mas nos demais rios onde o $\mathrm{pH}$ é acima de 6 , as condições são muito favoráveis", segundo o site portalamazonia. Os rios da Amazônia podem ser separados em rios de água preta, rios de água branca e rios de água clara. O molusco não encontraria um ambiente favorável em rios de água preta, como o Rio Negro, onde o pH varia entre 3,5 e 4,0. Nem tanto em rios de águas claras como Xingu, Tapajós e Tocantins, onde o $\mathrm{pH}$ é de 4,0 a 7,0. No entanto, em rios de água branca como os rios Amazonas, Branco, Madeira, Juruá e Purus, que possuem pH 6,5 entre 7,0, o cenário seria favorável. Deste modo, o controle do despejo de água de lastro nesta região deve ser efetivo, para evitar a proliferação desta espécie invasora na região. Pereira et al. 2014 mostraram os riscos associados à qualidade da água despejada na bacia do rio Amazonas. Ainda neste livro iremos apresentar uma seção que irá tratar especificamente deste assunto.

Outro problema, detectado por empresas de aquacultura se deve ao ataque de algas tóxicas lançadas, juntamente com a água de lastro, em áreas próximas ao cultivo (COHEN, 1998). Os cistos de dinoflagelados, encontrando condições favoráveis, germinam e se reproduzem de forma intensa e formam manchas coloridas, denominadas marés vermelhas (BRASIL. SITUAÇÃO NACIONAL, 2007). As toxinas produzidas contaminam os organismos cultivados, que além de morrerem, tornam-se impróprios para o consumo humano por certo período, o que 
causa grande prejuízo ao aquacultor. Seeliger e Costa (2003) afirmam que água de lastro e a incrustação nos cascos de mais de 3.500 embarcações que circulam na bacia Patos-Mirim (RS) são responsáveis pela proliferação de algas que podem contribuir para o aparecimento de marés vermelhas.

Collyer (2007) explica que outra espécie exótica é o siri Charybdis hellerii, originário dos oceanos Índico e Pacífico, que chegou ao Brasil provavelmente na água de lastro colhida no Caribe. Hoje ele está presente na Baía de Todos os Santos (BA), e nas Baías de Sepetiba e Guanabara (RJ). Este siri, sem valor comercial, está substituindo as populações de caranguejos que têm importância pesqueira e vem causando prejuízos à comunidade de pescadores.

Por outro lado, a aquacultura pode ser uma grande porta aberta para entrada de espécies exóticas. A experiência mostra que os animais cultivados escapam para os ambientes naturais, mesmo quando confinados em sistemas fechados com todas as medidas de segurança e controle conhecidas (PERES e KLIPPEL, 2003). Embora os escapes tenham contribuído para parte dessas introduções, a maioria delas foi causada pela liberação intencional e massiva de indivíduos em corpos d'água naturais e seus barramentos, por programas de repovoamento de reservatórios e de aumento de estoque pesqueiro, também conhecidos por "peixamentos”. Cerca de vinte espécies exóticas ou invasoras de peixes foram liberadas em reservatórios das Bacias do sul e sudeste. Apenas na Bacia do Rio São Francisco, o governo federal liberou 38,7 milhões de peixes, entre 1995 e 1997 (VIEIRA e POMPEU, 2001).

Farrapeira et al. (2007) examinaram os cascos de 32 das 491 embarcações que atracaram no porto de Recife em 2006, oriundos de várias partes do mundo, para identificar possíveis espécies exóticas. Os autores analisaram os seguintes tipos de navios: pesqueiros, rebocadores, cargueiros, dragas e escola. Foram encontradas 60 espécies diferentes, sendo que algumas nunca tinham sido catalogadas anteriormente e apresentam alto risco de invasão.

Contudo, há poucos dados dos impactos de espécies exóticas sobre a biodiversidade do Brasil. Segundo Collyer (2007) já foram identificadas cerca de 30 espécies aquáticas invasoras, tendo a água de lastro como vetor principal. Os esparsos registros disponíveis indicam a eliminação ou redução de espécies nativas por competição e predação, a introdução de parasitas, e a alteração de processos do ecossistema.

Por exemplo, os EUA dispõem de um banco de dados de espécies invasoras disponível na internet denominado National Ballast Information Clearinghouse (NBIC), em que se pode fazer um acompanhamento da situação no país.

Os EUA desenvolveram sistemas de monitoramento e controle de espécies exóticas que permitem um acompanhamento de todo o processo da bioinvasão. Com base nestas informações podem ser adotadas medidas de controle para 
inibir a proliferação ou até a erradicação das espécies invasoras. Registros de espécies invasoras oriundas da água de lastro erradicadas no mundo estão apresentados em (HEWITT e CAMPBELL, 2007).

Lopes (2009) em parceria com o Ministério do Meio Ambiente - MMA publicou o Informe sobre as Espécies Exóticas Invasoras Marinhas no Brasil, catalogando 58 espécies no Brasil. Entre elas encontram-se fitoplâncton (5\%), zooplâcton (10\%), fibentos (9\%), zoobentos $(69 \%)$ e peixes (7\%). A origem é variada sendo oriundas do Indo Pacífico (30\%), Pacífico Oriental (14\%), Pacífico Ocidental/Caribe (10\% cada), Atlântico Oriental (8\%), Europa (5\%), Índico e Leste da África ( $2 \%$ cada). Este material é disponibilizado gratuitamente pelo MMA.

\subsection{PRINCIPAIS CONTAMINANTES CONTIDOS NA ÁGUA DE LASTRO}

As espécies contidas na água e no sedimento dos tanques de lastro dos navios podem sobreviver durante viagens transoceânicas. Uma grande quantidade de organismos de grupos taxonômicos ${ }^{1}$ distintos (vírus, bactérias, protistas, larvas/ ovos de invertebrados e de peixes), capturados com a água de lastro no porto de origem pode ser descarregada no porto de destino (NATIONAL RESEARCH COUNCIL, 1996).

A escala máxima do tamanho dos organismos que podem ser pegos em um navio depende do tamanho das telas de entrada localizadas na caixa de mar do navio. A água bombeada para os tanques de lastro carrega organismos através dos impulsores da bomba, que podem matar alguns desses organismos. No sistema de captação de água que está esquematizado na Figura 5, existem as telas externas e internas para proteção, através das quais os organismos maiores geralmente não podem passar. Entretanto, exceções podem ocorrer, permitindo o transporte desses organismos maiores, tais como peixes.

Entre as plantas transportadas, as microalgas do fitoplânctons ${ }^{2}$ foram comumente encontradas na água do lastro (CARLTON e GELLER, 1993; HALLEGRAEFF, 1993).

Entre os animais, o zooplâncton pode ser diverso e denso na água do lastro. Estão incluídos aqui organismos planctônicos ${ }^{3}$ que passam a maior parte ou todo

1 Taxonomia: A taxonomia é a área da biologia que trata da nomenclatura, identificação e classificação dos organismos.

2 Fitoplâncton é o organismo vegetal que, como o plâncton, vive em suspensão na água do mar e é arrastado pelo movimento da água.

3 Organismos planctônicos é conjunto de organismos, principalmente microscópicos, que flutuam em águas salgadas ou doces. 
seu ciclo de vida na água, tal como muitos tipos de protozoários, copépodas, camarão - gambá, lesma-seta (chaetognathos) e peixes. O zooplâncton também inclui aqueles animais planctônicos que passam somente uma parcela de suas vidas na coluna de água (meroplâncton), em particular as larvas de muitos invertebrados bentônicos, incluindo anêmonas do mar, corais, hidras, moluscos (caracóis, mexilhões, moluscos, ostras, e bivalves), crustáceos (cracas, camarão, lagostas, caranguejos, caranguejos-eremita), vermes marinhos poliquetas, equinodermos (estrelas-do-mar, estrelas frágeis, ouriços-do-mar, pepinos do mar), tunicados (Ascídias) e as larvas de peixes (NATIONAL RESEARCH COUNCIL, 1996).

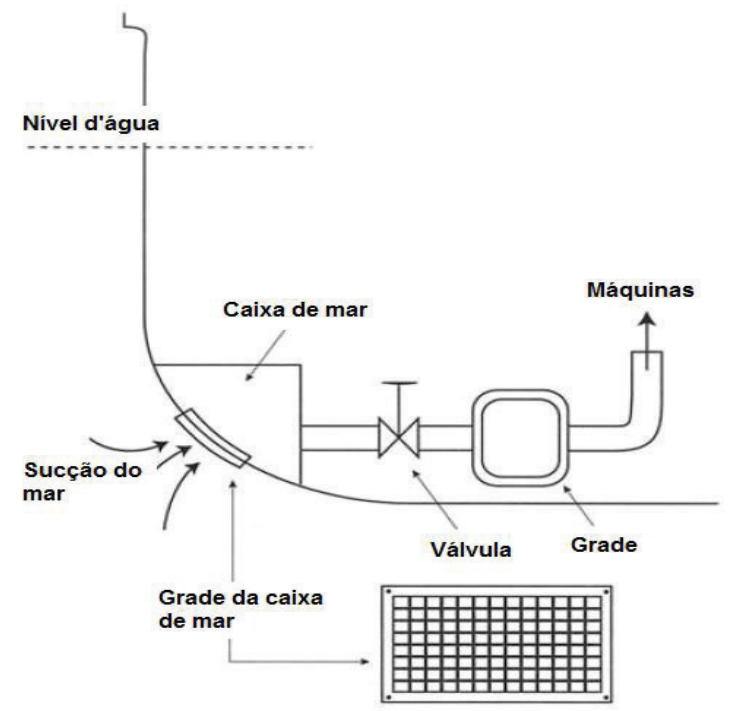

Figura 5 Esquema do sistema captação da água de lastro do mar Fonte: NATIONAL RESEARCH COUNCIL (1996)

A biota, ou seja, conjunto dos seres organismos (animais e vegetais, além de micro-organismos) pertencentes ao sedimento contido nos tanques dos navios não é totalmente conhecida, devido à variabilidade dos locais de coleta da água de lastro. Williams et al. (1988) relataram que as embarcações que chegavam na Austrália continham diversos e abundantes invertebrados que poderiam ser liberados quando o sedimento é descarregado. Hallegraeff e Bolch (1992) afirmaram que o sedimento dos tanques de lastro pode conter numerosos cistos e que a biota do sedimento nos tanques de lastro também não é totalmente conhecida. A Figura 6 mostra que no fundo dos tanques existe uma quantidade de água e de sedimentos que geralmente não são bombeados para fora dos tanques e oferecem condições propícias para proliferação de comunidades exóticas no local. 


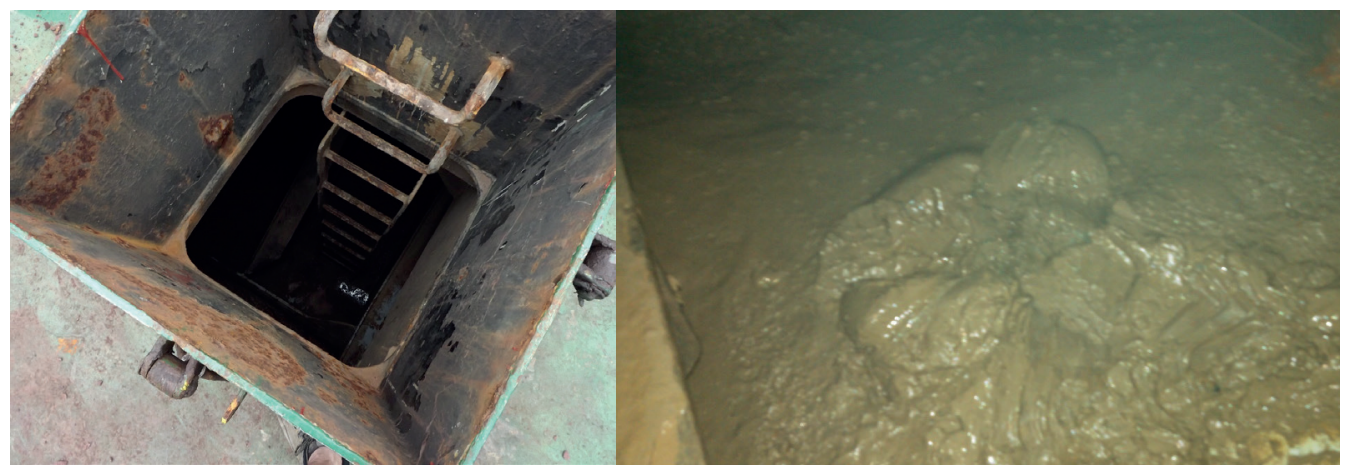

Figura 6 Acúmulo de sedimentos no fundo e na parede dos tanques

A Figura 7 e Figura 8 mostram os resultados de uma análise biológica realizada na água de lastro coletada dentro de um tanque de água de lastro de um navio atracado no porto de Santos. A água foi analisada em laboratório por meio de um microscópio e foram identificados os seguintes indivíduos vivos dentro do tanque. Cabe salientar, que água foi coletada e análise foi conduzida 10 dias após e os organismos ainda estavam vivos.

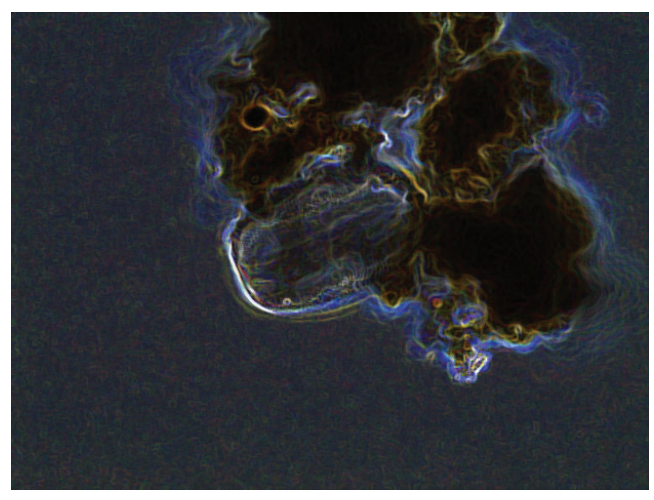

Figura 7 Dinoflagelado não identificado

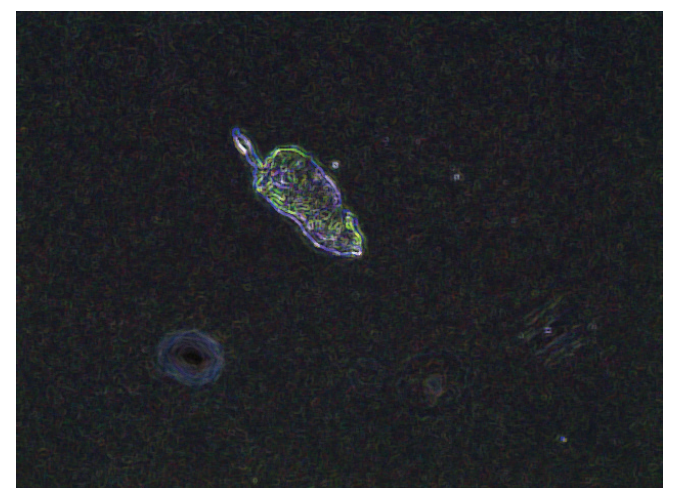

Figura 8 Matéria orgânica

Neste contexto, o comitê responsável pela elaboração do NATIONAL RESEARCH COUNCIL (1996) observou sedimentos estabelecidos na parte inferior de um tanque de lastro de uma embarcação que, quando a água de lastro já tinha sido esgotada, ainda retinha um lastro não bombeado, formando uma coluna d'água que variava de 15 a $30 \mathrm{~cm}$.

Junto com o sedimento existiam vermes, camarões, hidras e outras espécies estabelecidas no fundo do tanque. Estes organismos podiam liberar larvas planctônicas na água sobrejacente do lastro, que poderia subsequentemente ser descarregada, mantendo ainda uma comunidade adulta residente na parte inferior do tanque (NATIONAL RESEARCH COUNCIL, 1996). Deste modo, quando 
uma nova quantidade de água fosse captada, ela seria provavelmente impactada com os elementos que ficaram retidos no interior dos tanques.

Esses são indicativos importantes para que sejam desenvolvidas alternativas de gestão, monitoramento constante e tratamento do sedimento retido no fundo dos tanques de lastro dos navios. Deste modo, a atenção deve ser voltada não somente à água de lastro, mas ao sedimento que também é parte importante no processo de gestão ambiental.

\subsection{REFERÊNCIAS}

BELZ, C.E. Análise de risco de bioinvasão por Limnoperna fortunei (Dunker, 1857): um modelo para a bacia do Rio Iguaçu, Paraná. Tese (doutorado) Universidade Federal do Paraná, Setor de Ciências Biológicas, Programa de Pós-Graduação em Zoologia. Defesa: Curitiba, 2006.

BOLCH, C.J.; HALLEGRAEFF, G.M. Chemical and physical treatment options to kill toxic dinoflagellate cysts in ships' ballast water. Journal of Marine Environmental Engineering: 1993. 23-29 p.

CALIFORNIA ENVIRONMENTAL PROTECTION AGENCY - CAPA. Evaluation of Ballast Water Treatment Technology for Control of 14 Nonindigenous Aquatic Organisms. State Water Resources Control Board, Sacramento, CA. 2002. 70 p.

CARLTON, J.T. et al. Shipping Study. The Role of Shipping in 31 the Introduction of Nonindigenous Aquatic Organisms to the Coastal Waters of the United States 32 (other than the Great Lakes) and an Analysis of Control Options. Report No. CG-D-11-95, U. S. 33 Coast Guard, Groton CT and U. S. Dept. of Transportation, Washington DC. 1995.

CARLTON, J.T. et al. Transoceanic and inter-oceanic dispersal of coastal marine organisms: The biology of ballast water. Oceanography and Marine Biology: an Annual Review, v.23. 1995.

CARLTON, J.T.; GELLER, J.B. Ecological roulette: the global transport and invasion of nonindigenous marine organisms. Science, 261: 1993. 78-82 p.

CARMO, M.C. Água de lastro. Ministério da defesa exército brasileiro Secretaria de ciência e tecnologia instituto militar de engenharia. 2006Pestana et al. (2002) apud Darrigran (2002)

COHEN, A.N. Ships' Ballast Water and the Introduction of Exotic Organisms into the San 11 Francisco Estuary: Current Problem Status and Management Options. Report for California Bay 12 Delta Authority, Sacramento, CA. San Francisco Estuary Institute, Richmond, CA. 1998.

COHEN, A.N., and James T. Carlton. "Nonindigenous aquatic species in a United States estuary.” (1995).

COLLYER, W. Água de lastro, bioinvasão e resposta internacional. Revista Jurídica. Presidencia da Republica. 2007. 
FARRAPEIRA, C. M.R. et al. "Ship hull fouling in the Port of Recife, Pernambuco." Brazilian Journal of Oceanography 55.3 (2007): 207-221.

GLOBALLAST WATER MANAGEMENT PROGRAMME, On guidelines and standards for ballast water sampling. Monograph. 2003.

GOLLASCH, S. et al. Critical review of the IMO international convention on the management of ships' ballast water and sediments. Harmful Algae, 6, 2007. 585-600.

HALLEGRAEFF, G.M. A review of harmful algal blooms and their apparent global increase. Phycologica 32. 1993. 79-99 p.

HALLEGRAEFF, G.M.; BOLCH, C.J. Transport of diatom a dinoflagellate resting spores in ships' ballast water: Implications for plankton biogeography and aquaculture. Journal of Plankton Research 14: 1992. 1067-1084p.

HEWITT, C.L.; CAMPBELL, M.L. "Mechanisms for the prevention of marine bioinvasions for better biosecurity.” Marine Pollution Bulletin 55.7 (2007): 395-401.

LOPES, R. Informe sobre as espécies exóticas invasoras marinhas no Brasil. Ministério do Meio Ambiente. 2009.

MANSUR, C.D. et al. Limnoperna fortunei (Dunker, 1857), molusco bivalve invasor, na bacia do Guaíba, Rio Grande do Sul. 2003.

MANSUR, C.D. et al. Limnoperna fortunei (Dunker, 1857), molusco bivalve invasor, na bacia do Guaíba, Rio Grande do Sul. 2003.

MEDEIROS, D. de Sá. Avaliação de risco da introdução de espécies marinhas exóticas por meio de água de lastro no Terminal Portuário de Ponta Ubu (ES). IPT. 2004.

OLIVEIRA, U.C. Gerenciamento de água de lastro nos portos. III Congresso de Oceanografia. 2008.

PIMENTEL, D. et al. Update on the environmental and economic costs associated with alien-invasive species in the United States. Ecological Economics. 2004.

REZENDE, M.F. Variação das características hidráulicas em condutos forçados devido à infestação pelo Limnoperna fortunei. Dissertação apresentada à Universidade Federal de Minas Gerais Programa de Pós-Graduação em Saneamento, Meio Ambiente e Recursos Hídricos. 2007.

SEELIGER, U.; COSTA, C. S. B. Alterações de Hábitats. Devido às Atividades Antrópicas na Costa Sul do Brasil. Anais do VI Congresso de Ecologia do Brasil (CEB, Fortaleza-CE). 2003.

VIEIRA, F.; POMPEU, P.S. Peixamentos: uma ferramenta para conservação da ictiofauna nativa?. Ciência Hoje, Rio de Janeiro, v. 30, n. 175, 2001. 28-33 p.

WILLIAMS, R.J. Cargo vessel ballast water as a vector for the transport of nonindigenous marine species. Estuarine and Coastal Shelf Science 26. 1988. 409-420 p. 